\title{
Synthesis and Study of Water-Soluble Polymers Produced from Furfural and Levulinic Acid
}

\author{
Mikhail Yu. Chernyak, Valery E. Tarabanko*, \\ Alexander A. Kondrasenko and Maria S. El'berg \\ Institute of Chemistry and Chemical Technology SB RAS \\ FRC "Krasnoyarsk Science Center SB RAS" \\ 50/24 Akademgorodok, Krasnoyarsk, 660036, Russia
}

Received 06.04.2018, received in revised form 21.04.2018, accepted 30.05.2018

Synthetic water-soluble macromolecules are substances that may modify the physical properties of aqueous systems and have a wide range of industrial applications. The product of aldol reaction of furfural and levulinic acid, 3,5-difurfurylidenelevulinic acid, are obtained and characterized. This compound is shown to be polymerized by the acid or alkaline catalysts into water-soluble polymers.

Keywords: 3,5-difurfurylidenelevulinic acid, furfural, levulinic acid, polymerization, aldol reaction.

Citation: Chernyak M.Yu., Tarabanko V.E., Kondrasenko A.A., El’berg M.S. Synthesis and study of water-soluble polymers produced from furfural and levulinic acid, J. Sib. Fed. Univ. Chem., 2018, 11(2), 273-280. DOI: 10.17516/1998-2836-0074.

\section{Синтез и изучение водорастворимых}

\section{полимеров фуранальдегида и левулиновой кислоты}

М.Ю. Черняк, В.Е. Тарабанько, А.А. Кондрасенко, М.С. Эльберг Институт химии и химической технологии СО РАН ФИЦ «Красноярский научный центр СО РАН» Россия, 660036, Красноярск, Академгородок, 50/24

Синтетическиеводорастворимыеполимерыиспользуютсявпромымленностидлямодификации свойств водных растворов и систем. Получен и охарактеризован продукт кротоновой

(C) Siberian Federal University. All rights reserved

* Corresponding author E-mail address: veta@icct.ru 
конденсации фуранальдегида и левулиновой кислоть - 3,5-дифурфурилиденлевулиновая кислота. Показанавозможность получения водорастворимых полимеров путем полимеризации 3,5-дифурфурилиденлевулиновой кислоть в условиях кислотного и щелочного катализа.

Ключевые слова: 3,5-дифурфурилиденлевулиновая кислота, фуранальдегид, фурфурол, левулиновая кислота, полимеризация, поликонденсация, кротоновая конденсация, альдольная конденсация.

\section{Введение}

Синтез новых полимеров из возобновляемого растительного сырья - интенсивно развивающаяся область исследований [1-3]. Левулиновая кислота и фуранальдегид являются одними из наиболее перспективных прекурсоров органического синтеза, получаемых в процессах химической переработки древесины $[4,5]$. Альдольная конденсация фуранальдегида (1) и левулиновой кислоты (2) в щелочной среде приводит к образованию соответствующих $\beta$-гидроксикетонов и последующим продуктам элиминирования (кротоновой конденсации) 3-фурфурилиденлевулиновой (3) и 3,5-дифурфурилиденлевулиновой (4) кислот согласно схеме [6], приведенной на рис. 1.

Протоны 5-метильной и 3-метиленовой групп левулиновой кислоты имеют близкую активность в процессах енолизации основаниями, и это может приводить к образованию изомерных продуктов конденсации. Образование 3-фурфурилиденлевулиновой кислоты под действием оксида цинка описано в [6].

Гидрирование продуктов конденсации (3) и (4) дает длинноцепочечные алифатические кислоты, которые широко используются для получения поверхностно-активных веществ, лекарств, лубрикантов, пластификаторов. Возможно гидрирование (3), (4) до длинноцепочечных и разветвленных алканов топливного назначения [7, 8].

3-фурфурилиденлевулиновая и 3,5-дифурфурилиденлевулиновая кислоты содержат в своей структуре двойные связи и карбонильную группу, способные в определенных условиях полимеризоваться и конденсироваться, однако такие процессы в литературе практически не описаны. Предположение об образовании полимера взаимодействием левулиновой кислоты и фуранальдегида в водно-щелочной среде (реакция Михаэля) описано в [9].

Цель настоящей работы заключается в исследовании взаимодействия фуранальдегида и левулиновой кислоты и возможности получения водорастворимых полимеров на их основе.

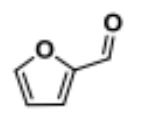

(1)

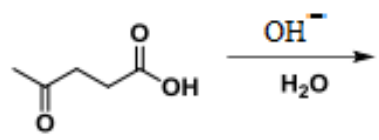

(2)

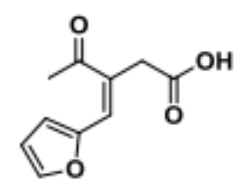

(3)

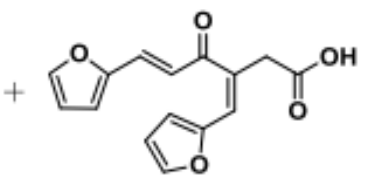

(4)

Рис. 1. Схема конденсации фуранальдегида и левулиновой кислоты

Fig. 1. Aldol condensation of furfural with levulinic acid

$$
-274-
$$




\section{Экспериментальная часть}

В работе использовались следующие материалы и реактивы: дистиллированная вода, этанол (фармацевтический для наружного применения 96 \%), левулиновая кислота 98 \% Acros organics, гидроксид натрия «х.ч.», фуранальдегид «ч», хлористоводородная кислота 36 \% «х.ч.», Химреактивснаб, дейтерированные растворители для ${ }^{1} \mathrm{H}-Я \mathrm{MP-спектроскопии}\left(\mathrm{D}_{2} \mathrm{O} 99\right.$ \%, диметилсульфоксид 99,9 \% и хлороформ 99,8 \% Cambridge Isotope Laboratories Inc.).

Инструментальные методы анализа. Спектры ЯМР записывались на приборе Bruker Avance III $600 \mathrm{MHz}$ Центра коллективного пользования Красноярского научного центра СО PAH.

Получение 3,5-дифурфурилиденлевулиновой кислоты (ДФЛК). ДФЛК была синтезирована, согласно [9], конденсацией левулиновой кислоты и фуранальдегида с единственным отличием - в молярном отношении реагентов 1:2 (вместо 1:1 в [9]) в водно-щелочной среде. Смесь фуранальдегида (1,92 г, 20 ммоль) и левулиновой кислоты (1,16 г, 10 ммоль) в 20 мл воды охлаждали до $0{ }^{\circ} \mathrm{C}$. Раствор гидроксида натрия $(0,68$ г, 17 ммоль) в 30 мл воды также охлаждали до $0{ }^{\circ} \mathrm{C}$. Раствор гидроксида натрия постепенно вливали в раствор фуранальдегида и левулиновой кислоты при перемешивании. Перемешивание продолжали при комнатной температуре в течение 48 ч, после чего подкисляли реакционную массу 1,0 М раствором хлористоводородной кислоты. Выпавший осадок продукта промывали водой до нейтральной реакции и сушили на воздухе.

Полимеризация 3,5-дифурфурилиденлевулиновой кислоты. Процесс проводился в стеклянной пробирке при комнатной температуре. 100 мг ДФЛК растворяли в 10 мл хлороформа. Пробирку помещали в герметично закрывающийся эксикатор, в котором проводили насыщение газообразным хлористым водородом. Генерация хлористого водорода осуществлялась действием концентрированной хлористоводородной кислоты на безводный хлорид кальция. Полимеризацию ДФЛК в виде пленки, нанесенной на стеклянную пластину под действием газообразного хлороводорода, проводили по аналогичной методике.

\section{Результаты и обсуждение}

\section{1. Взаимодействие фуранальдегида и левулиновой кислоть в водно-щелочной среде}

Изучено взаимодействие фуранальдегида и левулиновой кислоты в условиях методики синтеза полимера [9]. Высокомолекулярных продуктов взаимодействия в этих условиях нам получить не удалось. Наши результаты кардинально отличаются от данных, приведенных в цитированной статье [9]. Согласно [9], при взаимодействии эквимолярных смесей фуранальдегида и левулиновой кислоты в щелочной среде получен продукт конденсации по Михаэлю поли[1-карбоксиметил-4-(фуран-2-ил)-2-оксобутан-1,4-диил], спектр ПМР которого приведен на рис. 2.

При проведении конденсации фуранальдегида и левулиновой кислоты в молярном соотношении 1:1 в условиях [9] нами получена смесь мономерных соединений 3-фурфурилиденлевулиновой и 5-фурфурилиденлевулиновой кислот. Селективное (более 70 \%) образование 3-фурфурилиденлевулиновой и 5-фурфурилиденлевулиновой кислот в результате кротоновой конденсации фуранальдегида и левулината натрия в присутствии $\mathrm{ZnO}$ и $\mathrm{MgO}$ соответственно описано в [6]. 


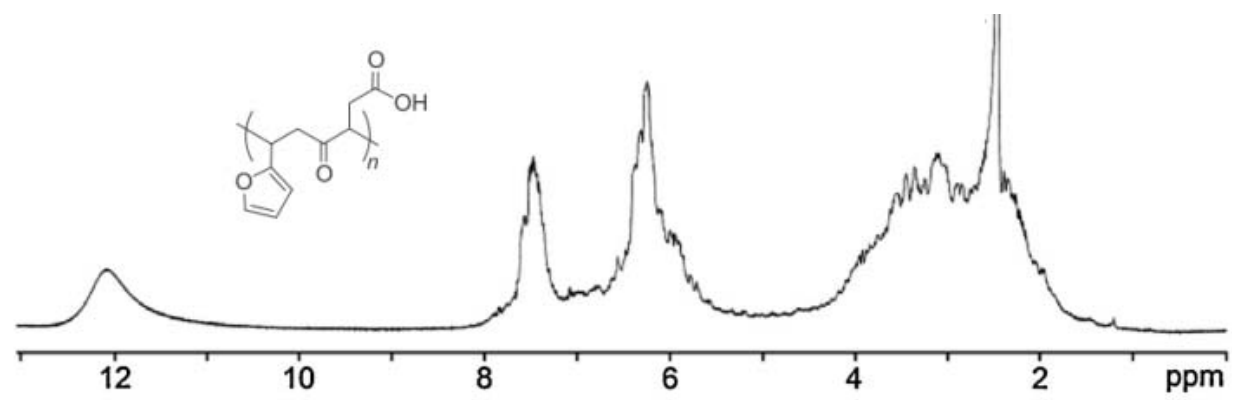

Рис. 2. ${ }^{1} \mathrm{H}$ ЯМР-спектр поли[1-карбоксиметил-4-(фуран-2-ил)-2-оксобутан-1,4-диила] в ДМСО-d6 [9]

Fig. 2. ${ }^{1} \mathrm{H}$ NMR spectra of poly[1-carboxymethyl-4-(furan-2-yl)-2-oxo-butane-1,4-diyl] in DMSO-d6 solvent [9]

2<smiles>CC(=O)CCC(=O)O</smiles><smiles>O=[N+]([O-])O</smiles><smiles>O=C(O)CC(=Cc1ccco1)C(=O)C=Cc1ccco1</smiles>

Рис. 3. Схема конденсации левулиновой кислоты и фуранальдегида в соотношении 1:2

Fig. 3. Aldol condensation of furfural with levulinic acid (mol ratio 1:2)

При использовании стехиометрии фуранальдегид:левулиновая кислота $=2: 1$ и более в условиях [9] также протекает кротоновая конденсация, и после подкисления реакционной массы выпадает коричневый осадок, который методом ПМР идентифицирован как мономерный продукт (рис. 3) стехиометрии 2:1, 3,5-дифурфурилиденлевулиновая кислота.

ДФЛК получена с выходом 80-85 \% от теоретического. Полученный коричневый аморфный порошок ограниченно (5-10 г/л) растворим в хлороформе, хорошо растворим в водно-щелочных растворах, этаноле. Сопоставимые выходы (80 \%) ДФЛК получены ранее конденсацией фуранальдегида и этиллевулината в щелочной среде $\left(50{ }^{\circ} \mathrm{C}, 12\right.$ ч) [8]. Механизм образования 3,5-дифурфурилиденлевулиновой кислоты под действием оснований описан как типичный процесс альдольной конденсации $[7,8]$.

ЯМР-спектры ( ${ }^{1} \mathrm{H}$ и ${ }^{13} \mathrm{C}$ ) ДФЛК в $\mathrm{CDCl}_{3}$ (рис. 4) совпадают со спектрами, представленными в [7]. ЯМР-спектры в $\mathrm{D}_{2} \mathrm{O}$ и их интерпретация в доступной литературе отсутствуют. Сопоставление спектров в дейтерированном хлороформе и тяжелой воде показывает, что в воднощелочной среде происходит быстрый обмен и усреднение винильных протонов. Очевидно, слияние цис- и трансконфигураций двойных связей в водно-щелочной среде происходит вследствие вращения вокруг оси двойной связи. Такая возможность открывается в водной среде, вероятно, в результате обратимой и быстрой гидратации двойной связи 5Л-6Ф, активированной сопряженной карбонильной группой, в результате чего происходит вращение вокруг этой связи.

Спектр ЯМР ${ }^{13} \mathrm{C}$ состоит из 15 сигналов, соответствующих атомам углерода в молекуле мономера: ${ }^{13} \mathrm{C}$ ЯMP (600 MHz, $\left.\mathrm{CDCl}_{3}, 25{ }^{\circ} \mathrm{C}, \mathrm{TMS}\right): \delta$ ppm 35.9 (s, 2л) 112.78 (s, 4') 112.93 (s, 4)

$$
-276-
$$



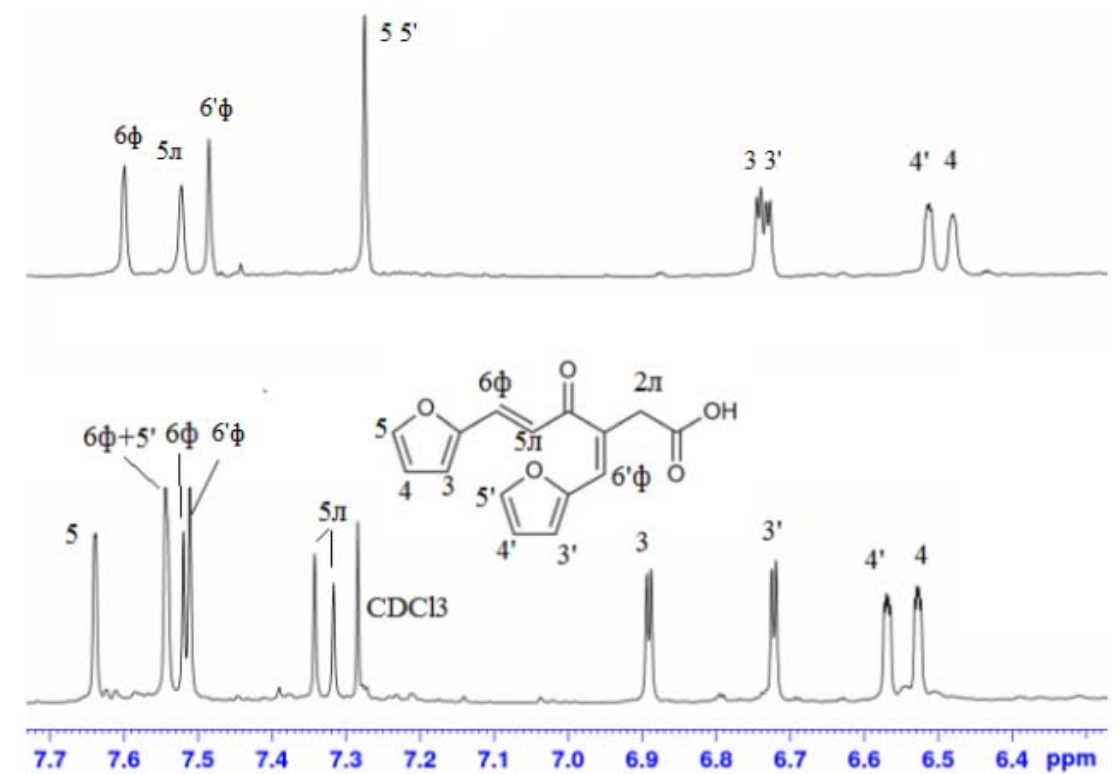

Рис. 4. ${ }^{1} \mathrm{H}$ ЯМР-спектр 3,5-дифурфурилиденлевулиновой кислоты в $\mathrm{CDCl}_{3}$ (внизу) и в $\mathrm{D}_{2} \mathrm{O}$ (вверху). Протоны 2Л- $\mathrm{CH}_{2}$-группы левулиновой кислоты (3,55 м.д.) не указаны. Индексами «ф» и «л» обозначены протоны фурфуролиденовых групп и левулиновой кислоты соответственно

Fig. 4. ${ }^{1} \mathrm{H}$ NMR spectra of 3,5-difurfurylidenelevulinic acid in $\mathrm{CDCl}_{3}$ solvent (bottom) and $\mathrm{D}_{2} \mathrm{O}$ (upper Figure). Protons of 2Л-CH2-groups of levulinic acid (3.55 ppm) are not shown. " $Ф$ " and “Л" indexes correspond to the proton signals of the furfurylidene groups and fragments of levulinic acid, accordingly

116.70 (s, 3’) 118.02 (s, 3) 118.55 (s, 5л) 129.10 (s, 6’ф) 130.45 (s, 6ф) 132.84 (s, 3л) 145.86 (s, 5') 146.44 (s, 5) 151.12 (s, 2') 151.41 (s, 2) 179.46 (s, 1л) 193.83 (s, 4л). Спектр ЯМР ${ }^{13} \mathrm{C}$ в [7] не интерпертирован.

Наличие карбоксильной группы в структуре 3,5-дифурфурилиденлевулиновой кислоты позволяет осаждать ее из щелочных раствором солями кальция. При этом образуется нерастворимый в водно-щелочных средах светло-серый аморфный порошок. Кальциевая соль 3,5-дифурфурилиденлевулиновой кислоты может быть использована в процессе очистки ДФЛК.

\section{2. Исследование полимеризации 3,5-дифурфурилиденлевулиновой кислоть}

Предприняты попытки провести радикальную полимеризацию ДФЛК, инициированную перекисью водорода и персульфатом натрия по двойным связям. Эксперименты проводили при 20-80 ${ }^{\circ} \mathrm{C}$ в водных растворах, в 0,1 M растворе гидроксида натрия и в карбонатных буферных системах (рН 7-8) при молярных отношениях инициатора $\left(\mathrm{H}_{2} \mathrm{O}_{2}\right.$ или $\left.\mathrm{Na}_{2} \mathrm{~S}_{2} \mathrm{O}_{8}\right)$ и ДФЛК от 1:10 до 1:1. Анализ ПМР спектров указывает на отсутствие процессов полимеризации и образование свободных фуранальдегида и левулиновой кислоты - продуктов ретроальдольного расщепления.

При насыщении раствора ДФЛК в хлороформе газообразным хлористым водородом (0,1 моль/литр) процесс полимеризации протекает при комнатной температуре. В течение 1-2 ч происходит потемнение реакционной массы, после чего из раствора в течение нескольких су-

$$
-277-
$$


ток выпадает черный осадок. Выделен полимерный продукт, порошок, практически нерастворимый в хлороформе, диметилсульфоксиде, дихлорметане. Полимер малорастворим и набухает в водном растворе щелочи.

Спектр ПМР водно-щелочного раствора продуктов полимеризации включает две широкие линии в областях 5,8-6,6 и 7,0-7,7 м.д. (рис. 5), относящиеся к собственно полимеру. Узкие сигналы на огибающей соответствуют протонам олигомеров. Следует отметить, что в спектре продуктов полимеризации в растворе отсутствует сигнал в области 7,2-7,4 м.д., принадлежащий протонам пятого положения фуранового кольца, а в углеродном спектре полимера отсутствует сигнал карбонильной группы. Эти два факта указывают на протекание полимеризации путем взаимодействия карбонильной группы (и затем спиртовой) с пятыми положениями фуранового кольца.

Под действием газообразного $\mathrm{HCl}$ олигомеризация ДФЛК протекает также в твердых пленках без растворителей. Такой продукт быстро и полностью растворяется в разбавленном водном растворе щелочи.

Определенный интерес вызывает факт образования полимерных продуктов из ДФЛК в условиях щелочного катализа при действии на нее концентрированной щелочи (40\%-ный раствор гидроксида натрия). При нагревании и перемешивании в концентрированной щелочи порошок ДФЛК не растворяется, расплавляется, темнеет, по охлаждении застывает в темную стеклообразную массу. Растворение в 1 М щелочи и подкисление полученного раствора дают полимерный продукт - светло-коричневый аморфный порошок, спектр ПМР которого представлен на рис. 6.

Спектр на рис. 6 имеет сходство со спектром полимерного продукта, синтезированного в [9] (рис. 2). Образование полимерного продукта в щелочной среде может свидетельствовать о протекании процесса по иному механизму, отличному от процесса в кислой среде. Наличие сигналов алифатических протонов в спектре полимерного продукта (рис. 6) позволяет предположить протекание полимеризации по олефиновым связям. В спектре полимера, полученного в кислой среде, сигналов алифатических протонов нет (рис. 5), что указывает на полимеризацию по карбонильным группам.

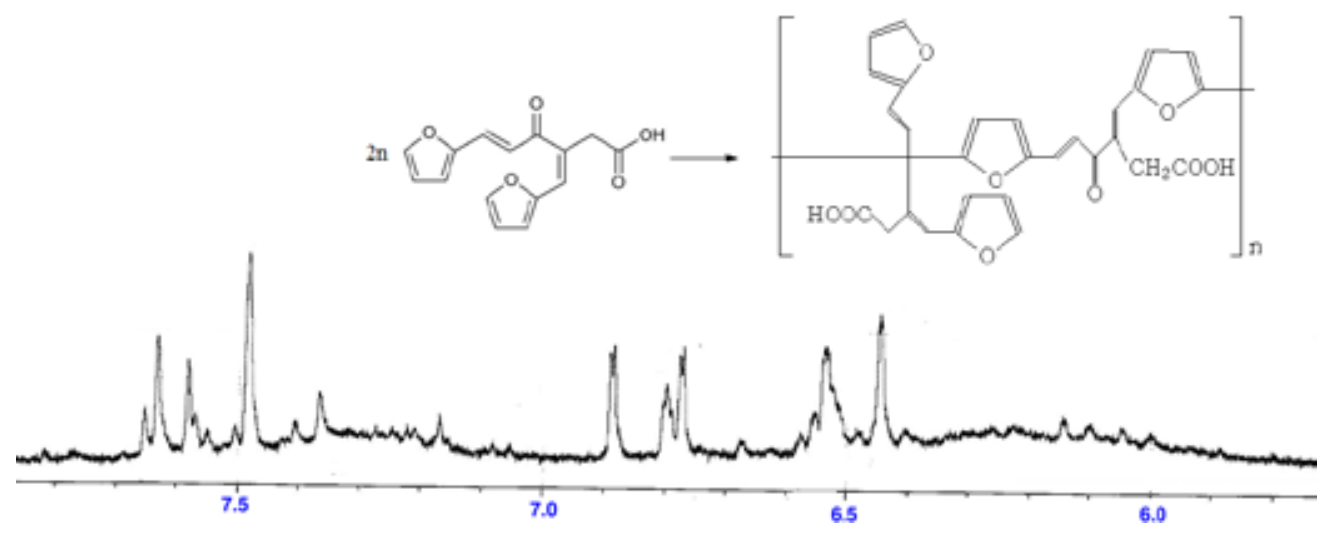

Рис. 5. ' $\mathrm{H}$ ЯМР-спектр продуктов полимеризации ДФЛК в растворе $\left(\mathrm{D}_{2} \mathrm{O}\right)$

Fig. 5. ${ }^{1} \mathrm{H}$ NMR spectra of 3,5-difurfurylidenelevulinic acidpolymeric products in $\mathrm{D}_{2} \mathrm{O}$ solvent

$$
-278-
$$




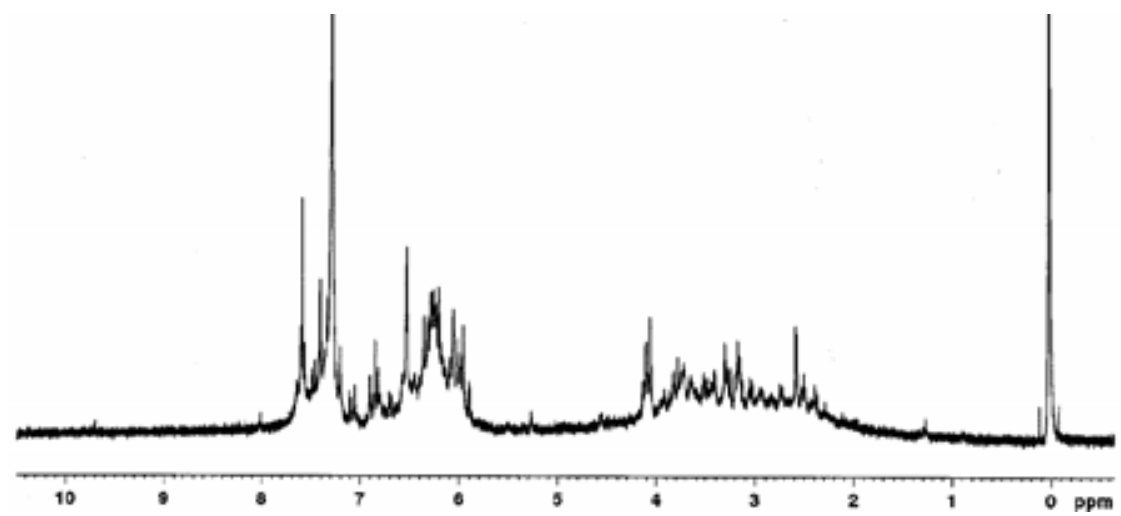

Рис. 6. ${ }^{1} \mathrm{H}$ ЯМР-спектр продуктов полимеризации ДФЛК в 40\%-ном растворе $\mathrm{NaOH}\left(\mathrm{CDCl}_{3}\right)$

Fig. 6. ${ }^{1} \mathrm{H}$ NMR spectra of 3,5-difurfurylidenelevulinic acidpolymeric products in $40 \% \mathrm{NaOH}\left(\mathrm{CDCl}_{3}\right.$ solvent)

\section{Заключение}

Взаимодействие фуранальдегида и левулиновой кислоты в водно-щелочной среде в условиях, описанных в [9], дает мономерные продукты кротоновой конденсации. Получен и охарактеризован основной продукт кротоновой конденсации - 3,5-дифурфурилиденлевулиновая кислота. ДФЛК полимеризуется в растворе в хлороформе и в массе под действием газообразного хлористого водорода путем взаимодействия карбонильной группы с фурановым кольцом. Полимеризация 3,5-дифурфурилиденлевулиновой кислоты протекает также под действием концентрированного водного раствора щелочи, по-видимому, путем раскрытия двойных связей. В обоих случаях образуются полимеры, растворимые в слабощелочных водных растворах вследствие диссоциации карбоксильной группы фрагмента левулиновой кислоты.

\section{Список литературы}

1. Fache M., Boutevin B., Caillol S. Vanillin production from lignin and its use as a renewable chemical. ACS Sustainable Chemistry \& Engineering 2016. Vol. 4, P. 35-46, http://doi.org/10.1021/ acssuschemeng.5b01344.

2. Tarabanko V.E., Tarabanko N. Catalytic oxidation of lignins into the aromatic aldehydes: general process trends and development prospects. International Journal of Molecular Sciences 2017. Vol. 18, P. 2421; doi:10.3390/ijms18112421.

3. Tarabanko N., Tarabanko V.E., Chernyak M.Yu., Kaygorodov K.L., Kondrasenko A.A., Maksimov N.G., Lutoshkin M.A., Pavlenko N.I. Synthesis of a polyconjugated polymer by aldol condensation of 2,5-diformylfuran and acetone. Journal of Siberian Federal University, Chemistry 2017. Vol. 10(4), C. 452-464; doi: 10.17516/1998-2836-0040.

4. Холькин Ю.И. Технология гидролизных производств. М.: Лесн. пром-ть, 1989. 496 с. [Khol'kin, Yu.I. Tekhnologiya gidroliznykh proizvodstv. Moscow: Lesnaya Promyshlennost', 1989. 496 p. (In Russ.)].

5. Tarabanko V.E., Smirnova M.A., Chernyak M.Yu., Kondrasenko A.A., Tarabanko N.V. The Nature and Mechanism of Selectivity Decrease of the Acid-catalyzed Fructose Conversion with 
Increasing the Carbohydrate Concentration. Journal of Siberian Federal University, Chemistry 2015. Vol. 8, No. 1, P. 6-18.

6. Guanfeng Liang, Aiqin Wang, Xiaochen Zhao, Nian Leiab and Tao Zhang. Selective aldol condensation of biomass-derived levulinic acid and furfural in aqueous-phase over $\mathrm{MgO}$ and $\mathrm{ZnO}$. Green Chemistry 2016. Vol. 18, P. 3430-3438. doi : 10.1039/C6GC00118A.

7. Xing-Long Li, Kun Zhang, Ju-Long Jiang, Rui Zhu, Wei-Peng Wu, Jin Deng and Yao Fu. Synthesis of medium-chain carboxylic acids or $\alpha, \omega$-dicarboxylic acids from cellulose-derived platform chemicals. Green Chemistry 2018. Vol. 20, P. 362-368. doi:10.1039/C7GC03125D.

8. Li C., Ding D., Xia Q., Liu X., Wang Y. Conversion of raw lignocellulosic biomass into branched long-chain alkanes through three tandem steps. ChemSusChem 2016. Vol. 9, P. 1-8. DOI: 10.1002/ cssc. 201600386

9. Ananda S. Amarasekara, Timila B. Singh, Eve Larkin, Muhammad A. Hasan, Hau-Jun Fan. $\mathrm{NaOH}$ catalyzed condensation reactions between levulinic acid and biomass derived furan-aldehydes in water. Industrial Crops and Products 2016. Vol. 65, P. 546-549. doi: 10.1016/j.indcrop.2014.10.005. 